\title{
Comparative study of single-dose and 24-hour multiple-dose antibiotic prophylaxis for cardiac surgery
}

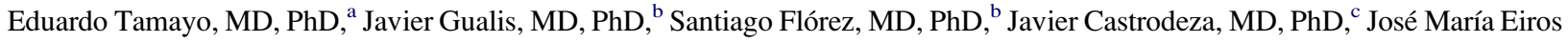 \\ Bouza, MD, PhD, ${ }^{\mathrm{d}}$ and Francisco Javier Álvarez, $\mathrm{MD}, \mathrm{PhD}^{\mathrm{e}}$
}

\begin{abstract}
Objective: Use of single-dose antibiotic prophylaxis is associated with reduced antibiotic resistance, lower costs, and fewer problems with drug toxicity and superinfections. We tested the hypothesis that single doses of cefazolin are as effective as a 24-hour regimen of cefazolin in preventing surgical site infections in adults undergoing cardiac procedures.

Methods: This random, prospective, clinical study included 838 adult patients undergoing elective coronary artery bypass grafting, valve operations, or both. These patients were randomly given a single dose of cefazolin $(2 \mathrm{~g})$ or a 24-hour treatment (2-g initial dose, followed by $1 \mathrm{~g}$ every 8 hours). Investigators blinded to the drug regimen diagnosed wound infections according to Centers for Disease Control and Prevention criteria. Patient clinical and demographic characteristics were noted, with follow-up for 12 postoperative months. The primary objective was to compare the incidence of surgical infections between groups up to 12 months postoperatively.
\end{abstract}

Results: A total of 419 patients received single-dose cefazolin, and another 419 received the 24-hour treatment. Surgical site infection occurred in 35 (8.3\%) patients receiving single doses and $15(3.6 \%)$ patients administered the 24-hour treatment $(P=.004)$. We identified no differences between groups for mortality or duration of hospitalization (preoperative hospitalization, intensive care unit stay, and hospitalization after surgical intervention). The microorganisms isolated showed a similar distribution in both groups. The germs isolated were gram-positive cocci in $86 \%$ of the surgical site infections.

Conclusions: Single-dose cefazolin used as antibiotic prophylaxis in cardiac surgery is associated with a higher surgical site infection rate than the 24-hour, multiple-dose cefazolin regimen.

Coronary artery bypass grafting and heart valve implantation are both common procedures. It is estimated that in the United States there are 468,000 bypass operations and more than 60,000 valve implantations ${ }^{1}$ carried out annually; in Europe the figures are 153,670 and 56,574, respectively. ${ }^{2}$ Surgical site infections (SSIs) in general are a serious complication after cardiac surgery, with a reported incidence of $0.25 \%$ to $25 \%{ }^{3,4}$ and a mortality rate of up to $31 \% .^{3,4}$ Sternal wound infections also constitute an economic burden to the health care system, with reported costs for their treatment of US $\$ 14,000$ to $\$ 40,000 .^{5}$

Antibiotic prophylaxis is used to avoid SSIs. ${ }^{3,4}$ The firstgeneration cephalosporins (cefazolin) are used most frequently ${ }^{3,4,6,7}$ because the Staphylococcus species, particularly Staphylococcus aureus, rank among the most commonly found pathogens in cardiac surgery patients ${ }^{4,6,7}$;

From the Departments of Anaesthesiology and Reanimation, ${ }^{\mathrm{a}}$ Cardiac Surgery, ${ }^{\mathrm{b}}$ and Microbiology, ${ }^{\mathrm{d}}$ Valladolid University Hospital, Valladolid, Spain, and the Departments of Medicine and Public Health ${ }^{c}$ and Pharmacology and Therapeutics, ${ }^{\mathrm{e}}$ Faculty of Medicine, University of Valladolid, Valladolid, Spain.

Received for publication Feb 21, 2008; revisions received April 16, 2008; accepted for publication May 4, 2008.

Address for reprints: Eduardo Tamayo, MD, PhD, Department of Anaesthesiology and Reanimation, Valladolid University Hospital, 47005 Valladolid, Spain (E-mail address: tamayo@med.uva.es).

J Thorac Cardiovasc Surg 2008; 136:1522-7

$0022-5223 / \$ 34.00$

Copyright (C) 2008 by The American Association for Thoracic Surgery

doi:10.1016/j.jtcvs.2008.05.013 however, the overuse of antibiotics is associated with increased costs and the development of antimicrobial resistence. $^{8,9}$

In recent years, there has been increased interest in the potential clinical benefits of administering the antibiotic in a single dose. ${ }^{10-12}$ The benefits of single-dose antimicrobial prophylaxis are based on microbial first principles: reduced antimicrobial resistance, fewer problems with drug toxicity and superinfections, and reduced cost. ${ }^{3}$ However, most cardiac surgery units use multiple-dose antimicrobial prophylaxis that continues for 24 to 48 hours and often until all the drain tubes are removed. ${ }^{3,9}$ There is no consensus $3,4,7,8$ on the type of antibiotic prophylaxis, whether a single dose or multiple doses should be used, or the duration of administration. We should also add that many different types of antibiotics have been evaluated in this respect. ${ }^{13-20}$

Thus the aim of this study was to test the hypothesis that single doses of cefazolin are as effective as a 24-hour regimen of cefazolin in preventing SSIs in adults undergoing cardiac procedures. Our study population was drawn from patients undergoing operations in a tertiary-level Spanish hospital.

\section{MATERIALS AND METHODS Patients \\ The study was carried out between September 2003 and January 2007 in the Hospital Clínico Universitario, Valladolid, Spain, where approximately}




\section{Abbreviations and Acronyms \\ ICU $=$ intensive care unit \\ SSI $=$ surgical site infection}

450 cardiac operations are performed annually on adult patients. This study was approved by the hospital's research commission.

All adult patients ( $>18$ years of age) scheduled for cardiac valve surgery, coronary surgery, or both by means of mean sternotomy were initially included in the sample. Exclusion criteria were the presence of an active infection, the administration of antibiotherapy in the 48 hours before surgical intervention, emergency surgical intervention, or allergy to betalactamics; in addition, we did not include patients with transplants or who did not wish to participate in the study. All those who participated provided written informed consent.

\section{Randomized Assignation and Antibiotic Regimens}

A computerized table of aleatory numbers was used to randomize allocation, and the patients were divided into one of 2 groups. The single-dose group received $2 \mathrm{~g}$ of cefazolin intravenously between 20 to 30 minutes after the induction of anesthesia, whereas the 24-hour group was administered $2 \mathrm{~g}$ of cefazolin intravenously between 20 to 30 minutes after the induction of anesthesia, followed by $1 \mathrm{~g}$ every 8 hours. For all interventions lasting more than 3 hours, a new dose of $1 \mathrm{~g}$ of cefazolin was administered. The evaluation of the results was carried out by a single researcher who did not know the antibiotic prophylaxis regimen administered.

\section{Patient Evaluation}

During hospitalization, cardiac surgeons examined all patients daily. Specialists in infectious diseases evaluated and treated, in consultation with the cardiac surgeons, the patients who had perioperative infectious pathologies. In addition, cultures of the wound were also drawn when frankly purulent sternal drainage or dehiscence was observed. Samples were processed in the microbiology laboratory in accordance with standard procedures (in positive cultures, the type of microorganisms isolated were noted). Cardiac surgeons personally followed up with patients in the cardiac outpatient clinic for at least 1 year after discharge from the hospital.

\section{Definitions of SSIs}

The definitions of the Centers for Disease Control and Prevention were used throughout, ${ }^{21}$ and the surveillance process was uniform for the duration of the study. The criteria are described below.

Superficial SSI. The infection covers the skin and subcutaneous cellular tissue and is accompanied by one of the following: purulent drainage through the incision, positive results of incisional culture, and classic inflammatory signs that allow the wound to be opened by the surgeon except in cases in which the incisional culture was negative.

Deep incisional SSI. The infection involves the deep soft tissues of the incision with at least 1 of the following: purulent drainage through the deep incision, a deep incision that spontaneously dehisced or was deliberately opened by the surgeon when the patient had a fever (temperature $\geq 38^{\circ} \mathrm{C}$ ) or localized pain or tenderness (unless the results of an incisional culture were negative), or evidence of deep incision infection found in a direct examination or second operation.

Mediastinitis. An organ-space SSI characterized by one of the following: positive results of a culture obtained from mediastinal tissue or fluid during a surgical operation, patient fever (temperature $\geq 38^{\circ} \mathrm{C}$ ), sternal pain or instability, mediastinal involvement suggested by a computed tomographic scan, or organisms cultured from the mediastinal area.
Sternal osteomyelitis. An organ-space SSI indicated by persistent purulent drainage from the sternotomy and confirmed by microbiologic and histopathologic findings.

Endocarditis. An organ-space SSI characterized by Duke's critera. ${ }^{22}$ Stratification of the risk of SSIs. SSIs were stratified according to the National Nosocomial Infection Surveillance System risk index. ${ }^{23} \mathrm{Be}$ cause all surgical wounds included in our study were classified as clean, the index values ranged from 0 to a maximum of 2 .

In addition, for all patients, we noted demographic and clinical characteristics and the dates of intraoperative and postoperative surgery (Table 1). Nosocomial events present (sepsis, renal failure, and respiratory failure) were defined by using conventional criteria. ${ }^{24}$ The number of days of

TABLE 1. Demographics, clinical characteristics, and operative data for the patients in terms of the surgical operation performed

\begin{tabular}{lccc}
\hline Characteristics & $\begin{array}{c}\text { Single dose } \\
(\mathbf{n}=\mathbf{4 1 9})\end{array}$ & $\begin{array}{c}\mathbf{2 4 - h} \text { Regimen } \\
(\mathbf{n}=\mathbf{4 1 9})\end{array}$ & $\boldsymbol{P}$ value \\
\hline Preoperative values & & & \\
Age (y) & $67.5 \pm 10.5$ & $68.2 \pm 10.5$ & .36 \\
Sex (M/F) & $272 / 147$ & $247 / 172$ & .07 \\
Diabetes mellitus & $111(26.5)$ & $125(29.8)$ & .28 \\
Hypertension & $189(45.1)$ & $178(42.4)$ & .44 \\
Chronic renal failure & $18(4.3)$ & $22(5.2)$ & .51 \\
Respiratory disease & $76(18.1)$ & $94(22.4)$ & .12 \\
Peripheral vascular & $25(5.9)$ & $38(9.0)$ & .08 \\
$\quad$ disease & & & \\
Immunosuppression & $0(0)$ & $1(0.2)$ & .31 \\
Hematologic illness & $11(2.6)$ & $10(2.3)$ & .82 \\
NNIS Risk index & & & \\
Category 0 & $41(9.7)$ & $45(10.7)$ & .65 \\
Category 1 & $248(59.1)$ & $251(59.9)$ & .54 \\
$\quad$ Category 2 & $130(31.0)$ & $123(29.3)$ & .60 \\
Intraoperative values & & & \\
Valve & $141(33.6)$ & $147(35.1)$ & .66 \\
CABG & $169(40.3)$ & $173(41.3)$ & .67 \\
Valve+CABG & $109(26.0)$ & $99(23.6)$ & .42 \\
Unilateral ITA & $147(35.0)$ & $147(35.0)$ & .52 \\
Bilateral ITA & $11(2.6)$ & $7(1.6)$ & .23 \\
Total CPB time (min) & $92.85 \pm 37.58$ & $90.69 \pm 36.45$ & .40 \\
Aortic crossclamp & $66.73 \pm 27.76$ & $64.65 \pm 28.05$ & .28 \\
$\quad$ time (min) & & & \\
Hypothermia of CPB & $33.13 \pm 0.72$ & $33.09 \pm 0.58$ & .29 \\
Hto after CPB & $27.07 \pm 4.20$ & $26.48 \pm 4.07$ & .05 \\
Postoperative values & & & \\
Time to extubation (h) & $49.8 \pm 202.8$ & $41.9 \pm 148.8$ & .53 \\
Intra-aortic balloon pump & $5(1.1)$ & $14(3.3)$ & .03 \\
Red cell transfusion & & & \\
$\quad$ Patients & $261(62.3)$ & $216(51.5)$ & .01 \\
Atrial fibrillation & $17(4.0)$ & $21(5.0)$ & .30 \\
Respiratory failure & $28(6.6)$ & $23(5.4)$ & .28 \\
Acute renal failure & $21(5.0)$ & $27(6.4)$ & .22 \\
Renal replacement & $12(2.8)$ & $13(3.1)$ & .50 \\
\hline & & & \\
Sepsis & $17(4.0)$ & $18(4.2)$ & .50 \\
\hline
\end{tabular}

Values are expressed as numbers (percentages) and means \pm standard deviation NNIS, National Nosocomial Infection Surveillance System; $C A B G$, coronary artery bypass grafting; ITA, internal thoracic artery; $C P B$, cardiopulmonary bypass; Hto, hematocrit. 
preoperative hospitalization, days in the intensive care unit (ICU), and days of postsurgical hospitalization were all noted, as was postoperative mortality at 30,90 , and 365 days after the operation.

\section{Statistical Analysis}

Before we started this study, cefazolin was the routinely used antibiotic for prophylaxis in cardiac surgery in our hospital. We estimated the number of patients needed for an adequate examination of the hypothesis that cefazolin in single doses should at least equal the SSI rate for cefazolin administered over 24 hours. Estimating that the SSI rate in cardiac surgery is around $5 \%,{ }^{3,14,17,18,23}$ a total of 419 patients were required in each group for the study to be able to show a significant reduction of the SSI rate to less than $5 \%$ with an $\alpha$ level of .20 and $\beta$ error of .05 . The reduction to less than $5 \%$ was chosen in agreement with the median SSI rate reported by the National Nosocomial Infections Surveillance System for coronary artery bypass graft operations among patients in risk category $2 .^{23}$

The degree of statistical significance between the 2 groups was determined by using the Student $t$ test or the Wilcoxon rank sum test for continuous variables and by using the Fisher's exact test or $\chi^{2}$ test for categorical variables.

Kaplan-Meier estimates of mortality, along with risk ratios and 95 percent confidence intervals, were used to describe the relative risk of death. These curves were statistically compared with the log-rank test. Data were stored and analyzed with SPSS version 14.0 (SPSS, Inc, Chicago, Ill).

\section{RESULTS \\ Patient Characteristics}

Over the study period, a total of 1027 patients were included, and 189 were excluded for not receiving the randomized prophylactic antibiotherapy regimen, for receiving another antibiotherapy regimen for surgical prophylaxis, or for having an incomplete follow-up. A total of 838 patients completed the study: 419 received cefazolin in single doses, and 419 received the 24 -hour regimen. Table 1 shows their demographic and clinical characteristics, as well as the variables associated with the surgical intervention categorized with respect to the antibiotic regimen used. Both groups were homogeneous and comparable as far as their demographic profiles and clinical characteristics were concerned. Noteworthy findings include the fact that in the single-dose group the number of patients who had transfusions was significantly higher than for those in the 24-hour group $(62.3 \%$ vs $51.5 \%, P=.01$, Table 1 ).

\section{Outcomes}

Regarding the prevalence of infection in the analyzed series (Table 2), of the total number of patients, $50(5.9 \%)$ presented with an SSI. A total of 35 SSIs were documented $(8.3 \%)$ in the single-dose group and $15(3.6 \%)$ in the 24 hour group $(P=.004)$. The percentages of superficial $(P=$ $.007)$ and deep incisional $(P=.04)$ SSIs were higher in the single-dose group than in the 24-hour group. Organ-space SSIs were more frequent in the single-dose group, although this difference was not statistically significant (Table 2).

The duration of the hospitalization (preoperative hospitalization, mean ICU stay, and hospitalization after the operation) was similar $(P>.05)$ in both groups (Table 2$)$.
TABLE 2. Outcomes of 838 patients receiving single-dose versus 24hour prophylaxis

\begin{tabular}{|c|c|c|c|}
\hline Characteristics & $\begin{array}{l}\text { Single dose } \\
(\mathrm{n}=419)\end{array}$ & $\begin{array}{l}\text { 24-h Regimen } \\
\quad(n=419)\end{array}$ & $P$ value \\
\hline $\begin{array}{c}\text { Superficial and deep } \\
\text { incisional SSI }\end{array}$ & $21(5.0)$ & $7(1.7)$ & .007 \\
\hline Superficial incisional SSI & $16(3.8)$ & $7(1.7)$ & .04 \\
\hline Deep incisional SSI & $5(1.2)$ & 0 & .03 \\
\hline Organ-space SSI* & $14(3.3)^{*}$ & $8(1.9)$ & .19 \\
\hline Osteomyelitis $\dagger$ & $3(0.7)$ & $2(0.5)$ & .5 \\
\hline Mediastinitis $\dagger$ & $8(1.9)$ & $5(1.2)$ & .28 \\
\hline Endocarditis & $5(1.2)$ & $1(0.2)$ & .10 \\
\hline Total infection & $35(8.3)$ & $15(3.6)$ & .004 \\
\hline $\begin{array}{l}\text { Preoperative } \\
\quad \text { hospitalization (d) }\end{array}$ & $9.7 \pm 7.9$ & $10.8 \pm 10.3$ & .11 \\
\hline Mean ICU stay (d) & $10.3 \pm 10.9$ & $9.1 \pm 8.7$ & .09 \\
\hline $\begin{array}{l}\text { Duration of hospitalization } \\
\text { after the operation (d) }\end{array}$ & $14.75 \pm 15.8$ & $12.2 \pm 14.2$ & .25 \\
\hline Mortality, $30 \mathrm{~d}$ & $22(5.2)$ & $31(7.4)$ & .12 \\
\hline Mortality, $90 \mathrm{~d}$ & $29(6.9)$ & $37(8.8)$ & .18 \\
\hline Mortality, $365 \mathrm{~d}$ & $43(10.3)$ & $48(11.5)$ & .34 \\
\hline
\end{tabular}

\section{Mortality}

Mortality was similar in both groups (Table 2). KaplanMeier analysis shows that there were no significant differences between the groups in mortality at 30 days $(P=$ .112 by the stratified log-rank test), 90 days $(P=.112$ by the stratified log-rank test), or 365 days $(P=.357$ by the stratified log-rank test) (Fig 1).

\section{Microorganisms}

The pathogens isolated in the SSIs were similarly distributed in both groups $(P \geq .05$, Table 3$)$. In $43(86 \%)$ of the 50 patients with SSIs, the SSIs were gram-positive cocci. The most frequent microorganisms isolated were Staphylococcus epidermidis, followed by $S$ aureus. The gram-negative bacilli caused $24 \%$ (12/50 cases) of the SSIs. The polymicrobial infection rate was similar in both groups: 20 $(57.1 \%)$ of 35 infections in the single-dose group and 9 $(60.0 \%)$ of 15 infections in the 24-hour group.

\section{DISCUSSION}

The 2 most relevant findings of the study are first that the administration of cefazolin in a single-dose regimen is associated with a higher rate of SSIs compared with rates for patients receiving the 24-hour regimen $(8.3 \%$ vs $3.6 \%)$. Nevertheless, mortality was not increased in the singledose group during hospitalization (preoperative hospitalization, ICU stay, and hospitalization after the operation). Second, the study confirms that the germs most frequently 


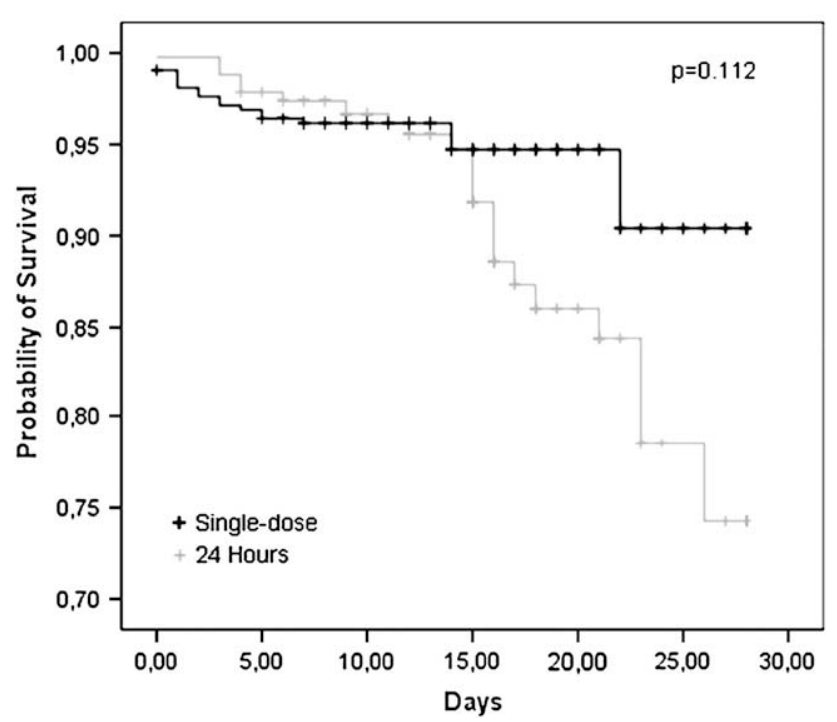

FIGURE 1. Kaplan-Meier estimates of survival among 838 patient receiving single-dose versus 24-hour prophylaxis.

causing SSIs are still the gram-positive cocci, in particular $S$ epidermidis, followed by $S$ aureus.

In other surgical specialties there is evidence that a single dose of antibiotic prophylaxis is sufficient to optimally reduce SSIs. ${ }^{17-19,25,26}$ A wide body of evidence in the literature supports this evidence based on both laboratory exper- iments and clinical trials. Burke ${ }^{27}$ first outlined the principle more than 45 years ago based on a series of experiments he performed using $S$ aureus in guinea pigs. He concluded that "...the effective period of prophylaxis begins the moment the bacteria gain access to the tissue and lasts approximately three hours."

The general consensus is that postoperative antibiotic prophylaxis should be stopped within 24 hours of most major procedures. ${ }^{3,7-12}$ However, in cardiac surgery this clinical practice has not been applied for several reasons. Cardiac surgeons have argued that there are many risk factors favoring SSIs in cardiac surgery, including (1) the cardiopulmonary bypass humoral compromise that occurs in the immunologic defenses, along with a reduction in phagocytosis and white blood cell activation, all of which impair the ability to neutralize infectious organisms; (2) the use of hypothermia; (3) the risk of postoperative bleeding; and (4) the length of the surgical procedures. ${ }^{3}$ Thus although cardiac surgeons have considered their patients to be high risk and have adopted a policy involving the use of antibiotics until removal of the chest and central intravenous lines, ${ }^{3,9}$ recent guidelines have indicated that antibiotic prophylaxis can be continued up to 48 hours after the operation. ${ }^{3}$

In the last 20 years, the question of optimum duration has not been adequately explored, with identical antibiotic regimens administered to groups differing only in the duration of

TABLE 3. Microorganisms isolated according to surgical site infections and antibiotic

\begin{tabular}{|c|c|c|c|c|c|c|}
\hline \multirow[b]{2}{*}{ Pathogens } & \multicolumn{3}{|c|}{ Single dose } & \multicolumn{3}{|c|}{ 24-h Regimen } \\
\hline & $\begin{array}{l}\text { Superficial and deep } \\
\text { incision }(n=21)\end{array}$ & $\begin{array}{c}\text { Organ space } \\
(\mathrm{n}=14)\end{array}$ & $\begin{array}{c}\text { Total } \\
(\mathbf{n}=\mathbf{3 5})\end{array}$ & $\begin{array}{l}\text { Superficial and deep } \\
\text { incision }(n=7)\end{array}$ & $\begin{array}{c}\text { Organ space } \\
(\mathbf{n}=\mathbf{8})\end{array}$ & $\begin{array}{c}\text { Total } \\
(\mathbf{n}=15)\end{array}$ \\
\hline \multicolumn{7}{|l|}{ Gram-positive cocci } \\
\hline All & $30(142.8)$ & $5(35.7)$ & $35(100.0)$ & $12(171.4)$ & $6(75.5)$ & $18(120.0)$ \\
\hline \multicolumn{7}{|l|}{ Staphylococcus aureus } \\
\hline All & $9(42.8)$ & $2(14.2)$ & $11(31.4)$ & $5(71.4)$ & 0 & $6(40.0)$ \\
\hline Methicillin resistant & $3(14.3)$ & $1(7.1)$ & $4(11.4)$ & $1(14.3)$ & 0 & $1(6.6)$ \\
\hline Methicillin susceptible & $6(28.6)$ & $1(7.1)$ & $7(20.0)$ & $4(57.1)$ & 0 & $5(33.3)$ \\
\hline \multicolumn{7}{|l|}{ Staphylococcus epidermidis } \\
\hline All & $19(90.4)$ & $1(7.1)$ & $20(57.1)$ & $5(71.4)$ & $3(37.5)$ & $9(60.0)$ \\
\hline Methicillin resistant & $11(52.4)$ & $1(7.1)$ & $12(34.3)$ & $2(28.6)$ & $3(37.5)$ & $5(33.3)$ \\
\hline Methicillin susceptible & $8(38.1)$ & 0 & $8(22.8)$ & $2(28.6)$ & 0 & $4(26.6)$ \\
\hline Other Staphylococcus species & 0 & $1(7.1)$ & $1(2.8)$ & $1(14.3)$ & & $2(13.3)$ \\
\hline Streptococcus mitis & 0 & $1(7.1)$ & $1(2.8)$ & 0 & 0 & 0 \\
\hline Enterococcus faecium & 0 & 0 & 0 & $1(14.3)$ & 0 & $1(6.6)$ \\
\hline Enterococcus faecalis & 2 & 0 & $2(5.7)$ & 0 & 0 & 0 \\
\hline \multicolumn{7}{|l|}{ Gram-negative bacilli } \\
\hline All & $6(28.6)$ & $2(14.2)$ & $8(22.8)$ & $2(28.6)$ & $2(25.0)$ & $4(26.6)$ \\
\hline Pseudomonas aeruginosa & 0 & $1(7.1)$ & $1(2.8)$ & 0 & 0 & 0 \\
\hline Klebsiella pneumoniae & $1(4.7)$ & $1(7.1)$ & $2(5.7)$ & $1(14.3)$ & 0 & $1(6.6)$ \\
\hline Enterobacter cloacae & 0 & 0 & 0 & 0 & $1(12.5)$ & $1(6.6)$ \\
\hline Proteus mirabilis & $2(9.5)$ & 0 & $2(5.7)$ & 0 & 0 & 0 \\
\hline Acinetobacter baumannii & $1(4.7)$ & 0 & $1(2.8)$ & $1(14.3)$ & 0 & $1(6.6)$ \\
\hline Other & $2(9.5)$ & 0 & $2(5.7)$ & 0 & $1(12.5)$ & $1(6.6)$ \\
\hline
\end{tabular}

Values are expressed as numbers (percentages). None of these differences is significant at a $P$ value of less than .05 . Some infections were polymicrobial. 
prophylaxis. ${ }^{13-20}$ It has therefore not been clearly established which regimen of antibiotic prophylaxis is the best.

The studies by Bucknell and associates (cefazolin vs teicoplanin and ticarcillin/clavulanate), ${ }^{13}$ Kriaras and colleagues (cefuroxime vs amoxicillin-netilmicin), ${ }^{14}$ Salminen and coworkers (ceftriaxone vs vancomycin), ${ }^{15}$ Saginur and associates (teicoplanin vs cefazolin), ${ }^{16}$ Sisto and colleagues (ceftriaxone vs cefuroxime), ${ }^{17}$ Hall and coworkers (ceftriaxone vs flucloxacillin and gentamicin), ${ }^{18}$ and Beam and associates (ceftriaxone vs cefazolin) ${ }^{19}$ all involve at least 1 antibiotic in the multiple-dose arm that was different from the antibiotic used in the single-dose arm. Other authors, such as Nooyen and colleagues, ${ }^{20}$ in a prospective randomized study, compared a single dose and a 3-day course of cefuroxime and concluded that in coronary artery bypass grafting a single dose of cefuroxime is as effective as a 3day course in the prevention of wound infection. However, this study evaluated the SSIs only over 7 postoperative days. This limitation is important because it is well known that sternal infections usually manifest themselves from the second postoperative week onward. ${ }^{3}$

With these types of study design, whether the specific antibiotic, the duration, or both account for the observed SSI incidence cannot be determined. Thus no conclusion is possible concerning the efficacy of the single-dose over the 24hour regimen. As we have seen, the results of our study show a higher rate of SSIs with single-dose prophylaxis compared with the 24-hour regimen, although this difference does not extend to either the duration of hospital stay or to mortality. Our study has the advantage of comparing the same antibiotic (cefazolin) and the fact that the main aim was to determine the efficiency of the antibiotic prophylaxis in a single dose as opposed to a 24-hour regimen.

Cardiac surgery is essentially a clean operation that should be associated with an infection rate of less than $5 \%{ }^{7-12}$ The overall SSI rate varies widely from one unit to another, with ranges between $0.25 \%$ to $25 \% .^{2-4}$ Our SSI data are within the ranges described in the literature.

Cefazolin was used as the antibiotic because the cephalosporin group of antibiotics, in particular the first- and second-generation agents, are the drugs most commonly used as surgical antibiotic prophylaxis in cardiac surgery., 3 ,-12 In spite of the extensive number of studies, no cephalosporin has been proved to be clearly superior in diminishing the rate of SSIs. ${ }^{3,7-12}$ The use of vancomycin for prophylaxis in cardiac surgery is much more controversial, although there are studies suggesting that vancomycin is superior to the cephalosporins and reduces the infection rate of mediastinitis. ${ }^{28}$ On the other hand, 2 major problems arising from the use of vancomycin in surgical prophylaxis deserve serious consideration: its association with adverse effects (hypotension and red man syndrome $)^{29}$ and the presence of vancomycinresistant enterococci and glycopeptide intermediate-resistant $S$ aureus. ${ }^{3,30}$
Regarding limitations, we should point out that this study did not evaluate the efficacy of the single-dose regimen in emergency cardiac surgery. In addition, it is not a multicenter study, and it might be necessary to carry out a further study of such characteristics to confirm the current results.

This randomized, prospective, clinical study was designed to verify the hypothesis that in adults undergoing elective cardiac procedures a single dose of cefazolin compared with a 24-hour regimen of cefazolin is just as effective in preventing SSIs. Both groups analyzed were homogeneous as far as their demographic and clinical data were concerned, and the sample size was sufficient to compare both groups. We found a higher rate of SSIs when single-dose cefazolin was used as the antibiotic prophylaxis in cardiac surgery as opposed to its use in multiple doses over 24 hours. However, there were no differences in mortality rate or length of hospital stay. The germs most frequently found to be the cause of SSIs were the gram-positive cocci. The results indicate that multiple doses of cefazolin over 24 hours should be used instead of single doses in surgical prophylaxis for cardiac surgery procedures.

\section{References}

1. Friberg Ö, Svedjeholm R, Söderquist B, Granfeldt H, Vikerfors T, Källman J. Local gentamicin reduces sternal wound infections after cardiac surgery: a randomized controlled trial. Ann Thorac Surg. 2005;79:153-61.

2. Unger F. Open heart surgery in Europe 1993. Eur J Cardiothorac Surg. 1996;10: $120-8$.

3. Edwards FH, Engelman RM, Houck P, Shahian DM, Bridges CR. Society of Thoracic Surgeons. The Society of Thoracic Surgeons practice guideline series: antibiotic prophylaxis in cardiac surgery, part i: duration. Ann Thorac Surg. 2006;81: 397-404.

4. Engelman R, Shahian D, Shemin R, Guy TS, Bratzler D, Edwards F, et al. The Society of Thoracic Surgeons practice guideline series: antibiotic prophylaxis in cardiac surgery, part II: antibiotic choice. Ann Thorac Surg. 2007;83:1569-76.

5. Hollenbeak CS, Murphy D, Dunagan WC, Fraser VJ. Nonrandom selection and the attributable cost of surgical-site infections. Infect Control Hosp Epidemiol. 2002;23:177-82.

6. Tamayo E, Soria S, Castrodeza J, Álvarez FJ. An assessment of compliance with surgical prophylaxis protocols in a hospital. Eur J Anaesthesiol. 2004;21:923-5.

7. Bucknell SJ, Mohajeri M, Low J, McDonald M, Hill DG. Single-versus multipledose antibiotics prophylaxis for cardiac surgery. Aust NZJ Surg. 2000;70:409-11.

8. Gordon SM, Serkey JM, Keys TF, Ryan T, Fatica CA, Schmitt SK, et al. Secular trends in nosocomial bloodstream infections in a 55-bed cardiothoracic intensive care unit. Ann Thorac Surg. 1998;65:95-100.

9. Harbarth S, Samore MH, Lichtenberg D, Carmeli Y. Prolonged antibiotic prophylaxis after cardiovascular surgery and its effect on surgical site infections and antimicrobial resistance. Circulation. 2000;101:2916-21.

10. Kreter B, Woods M. Antibiotic prophylaxis for cardiothoracic operations. Metaanalysis of thirty years of clinical trials. JThorac Cardiovasc Surg. 1992;104:590-9.

11. Bratzler DW, Houck PM. Antimicrobial prophylaxis for surgery: an advisory statement from the National Surgical Infection Prevention Project. Clin Infect Dis. 2004;38:1706-15.

12. Gilbert ND, Moellering RC, Eliopoulos GM, Sande MA. The Sanford guide to antimicrobial therapy. 37th ed. Hyde Park, Vt: Antimicrobial Therapy, Inc; 2007.

13. Bucknell SJ, Mohajeri M, Low J, McDonald M, Hill DG. Single-versus multipledose antibiotics prophylaxis for cardiac surgery. Aust N ZJ Surg. 2000;70:409-11.

14. Kriaras I, Michalopoulos A, Michalis A, Palatianos G, Economopoulos G, Anagnostopoulos C, et al. Antibiotic prophylaxis in cardiac surgery. J Cardiovasc Surg (Torino). 1997;38:605-10.

15. Salminen US, Viljanen TU, Valtonen VV, Ikonen TE, Sahlman AE, Harjula AL. Ceftriaxone versus vancomycin prophylaxis in cardiovascular surgery. J Antimicrob Chemother. 1999;44:287-90. 
16. Saginur R, Croteau D, Bergeron MG. Comparative efficacy of teicoplanin and cefazolin for cardiac operation prophylaxis in 3027 patients. The ESPRIT Group. $J$ Thorac Cardiovasc Surg. 2000;120:1120-30.

17. Sisto T, Laurikka J, Tarkka MR. Ceftriaxone vs cefuroxime for infection prophylaxis in coronary bypass surgery. Scand J Thorac Cardiovasc Surg. 1994;28:143-8.

18. Hall JC, Christiansen K, Carter MJ, Edwards MG, Hodge AJ, Newman MA, et al. Antibiotic prophylaxis in cardiac operations. Ann Thorac Surg. 1993;56:916-22.

19. Beam T, Raab T, Spooner J, Balderman S, Aldridge J, Bhayana J. Single-dose antimicrobial prophylaxis in open heart surgery. Eur J Clin Microbiol. 1984;3: 598-604.

20. Nooyen SM, Overbeek BP, Brutel de la Rivière A, Storm AJ, Langemeyer JJ. Prospective randomised comparison of single-dose versus multiple-dose cefuroxime for prophylaxis in coronary artery bypass grafting. Eur J Clin Microbiol Infect Dis. 1994;13:1033-7.

21. Garner JS, Jarvis WR, Emori TG, Horan TC, Hughes JM. CDC definitions of nosocomial infections. In: Olmsted RN, ed. APIC infection control and applied epidemiology: principles and practice. St Louis: Mosby; 1996. p. A1-20.

22. Durack DT, Lukes AS, Bright DK. New criteria for diagnosis of infective endocarditis: utilization of specific echocardiographic findings. Duke Endocarditis Service. Am J Med. 1994;96:200-9.

23. National Nosocomial Infections Surveillance [NNIS] report, data summary from October 1986-April 1997, issued May 1997: a report from the NNIS System. Am J Infect Control. 1997;25:477-87.
24. Levy MM, Fink MP, Marshall JC, Abraham E, Angus D, Cook D, et al. International Sepsis Definitions Conference. 2001 SCCM/ ESICM/ ACCP/ ATS/ SIS International Sepsis Definitions Conference. Intensive Care Med. 2003;29: 530-8.

25. Culver DH, Horan TC, Gaynes RP, Martone WJ, Jarvis WR, Emori TG, et al. Surgical wound infection rates by wound class, operative procedure, and patient risk index. National Nosocomial Infections Surveillance System. Am J Med. 1991; 91(suppl):152S-7S.

26. McDonald M, Grabsch E, Marshall C, Forbes A. Single- versus multiple-dose antimicrobial prophylaxis for major surgery: a systematic review. Aust N Z J Surg. 1998;68:388-96.

27. Burke JF. The effective period of preventive antibiotic action in experimental incisions and dermal lesions. Surgery. 1961;50:161-8.

28. Maki DG, Bohn MJ, Stolz SM, Kroncke GM, Acher CW, Myerowitz PD. Comparative study of cefazolin, cefamandole, and vancomycin for surgical prophylaxis in cardiac and vascular operations. A double-blind randomized trial. $J$ Thorac Cardiovasc Surg. 1992;104:1423-34.

29. Tamayo E, Gomez-Herreras JI, Alvarez FJ. Are we making proper use of vancomcycin in clinical practice? Med Clin. 2004;124:396-7.

30. Finkelstein R, Rabino G, Mashiah T, Bar-El Y, Adler Z, Kertzman V, et al. Vancomycin versus cefazolin prophylaxis for cardiac surgery in the setting of a high prevalence of methicillin-resistant staphylococcal infections. J Thorac Cardiovasc Surg. 2002;123:326-32. 